\title{
Regional deposition of saline aerosols of different tonicities in normal and asthmatic subjects
}

\author{
P.R. Phipps*, I. Gonda*, S.D. Anderson**, D. Bailey++, G. Bautovich++
}

Regional deposition of saline aerosols of different tonicities in normal and asthmatic subjects. P.R. Phipps, I. Gonda, S.D. Anderson, D. Bailey, G. Bautovich. CERS Journals Ltd 1994.

ABSTRACT: Nonisotonic aerosols are frequently used in the diagnosis and therapy of lung disease. The purpose of this work was to study the difference in the pattern of deposition of aerosols containing aqueous solutions of different tonicities.

${ }^{99 \mathrm{~m} T e c h n e t i u m-d i e t h y l t r i a m i n e p e n t a a c e t i c ~ a c i d ~}\left({ }^{99 \mathrm{~m}}\right.$ Tc-DTPA)-labelled saline aerosols, with mass median aerodynamic diameter 3.7-3.8 $\mu \mathrm{m}$ and geometric standard deviation 1.4, were inhaled under reproducible breathing conditions on two occasions. Hypotonic and hypertonic solutions were used in 11 normals subjects, isotonic and hypertonic solutions in 9 asthmatics. The regional deposition was quantified by a penetration index measured with the help of a tomographic technique.

There was a small but significant increase $(6.7 \%)$ in the penetration index of the hypotonic as compared to the hypertonic aerosols in the normal subjects. The region that was markedly affected was the trachea. The differences in the penetration of the isotonic and hypertonic aerosols in the asthmatics appeared to be strongly dependent on the state of the airways at the time of the study.

These findings can be interpreted in terms of effects of growth or shrinkage of nonisotonic aerosols, as well as of airway narrowing, on regional deposition of aerosols. Tonicity of aerosols appears to affect their deposition both through physical and physiological mechanisms. This should be taken into account when interpreting the effects of inhaled aqueous solutions of various tonicities in patients in vivo.

Eur Respir J., 1994, 7, 1474-1482.
*Department of Pharmacy, University of Sydney, Sydney, Australia. Depts of **Thoracic and ${ }^{++}$Nuclear Medicine, Royal Prince Alfred Hospital, Camperdown, Australia. +MRC Cyclotron Unit, Hammersmith Hospital, London, UK.

Correspondence: I. Gonda

Genentech Inc.

460 Point San Bruno Boulevard

South San Francisco

CA 94080

USA

Keywords: Aerosol deposition aerosol tonicity

asthma

hyperresponsiveness

lung

Received: November 91993

Accepted after revision April 171994

Supported by the Asthma Foundation of New South Wales and a Commonwealth Postgraduate Scholarship (Australia) for PRP.
Our knowledge of deposition as a function of the aerodynamic size of inhaled particles comes largely from studies of "stable" aerosols, i.e., aerosols whose size does not change between the point of generation and deposition. However, the majority of therapeutic aerosols, as well as other aerosols with serious health effects $[1$, 2], are not stable in this sense [3]. Soluble drug particles have the capacity to undergo hygroscopic growth [4]. Many solutions for nebulizers are nonisotonic [5]. Nonisotonic saline aerosols are used in the assessment of airway hyperresponsiveness [6, 7].

Hypertonic aerosols are able to absorb water vapour from a humid environment until the droplet vapour pressure is in equilibrium with that of its surroundings, or until they are deposited. If the airway fluid is isotonic, then the droplets will reach equilibrium when they have absorbed enough water to become isotonic themselves. In so doing, they will increase in size. This could, in turn, affect the regional and total deposition pattern of the aerosol [8]. Hypotonic aerosol droplets are expected to behave in the opposite manner. Hyperand hypotonic droplets of the same initial size may, therefore, be deposited with different regional patterns $[9,10]$.

The effects of hygroscopic growth on deposition have been studied theoretically and experimentally in vitro [11-16], and in vivo [17-20]. However, until recently $[9,10,18]$, there have been no in vivo experimental data on the effect of growth or shrinkage on regional deposition of aerosols in humans.

Characteristics relating to the subject may also have a profound effect on the fate of inhaled aerosols. It has been shown that the reduction in airway calibre occurring during an episode of asthma will increase deposition in the proximal, relative to the distal, airways [21]. This is relevant to agents used for inhalational challenge tests, such as histamine [22], which may depend on the site of deposition for their effects. The prechallenge lung function and pattern of bronchoconstriction during the challenge may, therefore, alter the deposition pattern.

We have previously demonstrated the use of single photon emission computerized tomography (SPECT) as a sensitive method for distinguishing between the 
deposition patterns of large $(5.5 \mu \mathrm{m})$ and small $(2.6 \mu \mathrm{m})$ droplets [23]. Our aim in the study reported here was to mimic the inhalation of nonisotonic ultrasonic aerosols used in the assessment of bronchial hyperresponsiveness $[6,7]$ in which the Mist- $\mathrm{O}_{2}$-Gen ultrasonic nebulizer was used. Due to the large aerosol output from the Mist- $\mathrm{O}_{2}-\mathrm{Gen}$ nebulizer used in the diagnostic tests [24], a jet-nebulizer with similar droplet size characteristics was employed in the current study. We compared the regional deposition of 0.3 and $4.5 \% \mathrm{NaCl}$ aerosols of the same initial droplet diameter in normal subjects. The hypotonic aerosol was substituted with isotonic saline in the asthmatic subjects, in order to have a nonbronchoconstrictive control.

\section{Methods}

Eleven normal nonsmoking subjects ( 2 females, aged 20 yrs, and 9 males with mean age 22 yrs, range 19$24 \mathrm{yrs}$ ), with no history of asthma or any other obstructive airways disease and with normal lung function, participated in the first study. Nine otherwise healthy nonsmoking subjects ( 2 females, aged 20 and 30 yrs, 7 males with mean age 24 yrs, range $22-27$ yrs) with a documented history of asthma took part in the second study. The protocol for the experiments was approved by the Ethics Review Committee at the Royal Prince Alfred Hospital in Camperdown, NSW, Australia. All subjects gave written consent prior to their participation. The subjects inhaled under controlled breathing conditions on two separate occasions radiolabelled aerosols containing different concentrations of $\mathrm{NaCl}$. The lung function tests were carried out before and after the inhalation. The deposition of the radioaerosols was followed by scintigraphy.

\section{Penetration index of hyper- and hypotonic aerosols in normal subjects}

The droplet size distribution was determined by cascade impaction $[4,24,25]$. An Up-Draft (Hudson RCI, Temecula, CA, USA) jet nebulizer was used in this study. Using isotonic saline, the output of the jet nebulizer $\left(0.23 \mathrm{ml} \cdot \mathrm{min}^{-1}\right)$ was lower than that of the Mist$\mathrm{O}_{2}$-Gen ultrasonic nebulizer $\left(0.49 \mathrm{ml} \cdot \mathrm{min}^{-1}\right)$. The droplet sizes were similar (mass median aerodynamic diameter $(\mathrm{MMAD})=3.7 \pm 0.1 \mu \mathrm{m}$ for the hypertonic and 3.8 $\pm 0.1 \mu \mathrm{m}$ for the hypotonic aerosols, geometric standard deviation $\left(\sigma_{\mathrm{g}}\right)=1.4 \pm 0.1$ for both tonicities produced by the UpDraft, c.f. $\mathrm{MMAD}=3.6 \mu \mathrm{m}$ and $\sigma_{\mathrm{g}}=1.1$ for the Mist- $\mathrm{O}_{2}-$ Gen).

Using an aerosol inhalation circuit as described previously [23, 26, 27], the subjects inhaled the aerosol with dilution air supplied via a medical humidifier and exhaled through a filter and carbon dioxide absorber into a bag-in-a-box; this set-up does not cause a measurable change in the droplet size distribution of the aerosol prior to entry to the subject's mouth [9]. A microcomputer (PC XT, IBM Corp., Boca Raton, FL, USA) was used to display a target volume, frequency and flow rate, according to the previously determined respiratory pattern of that subject. The subject was instructed to follow this target whilst inhaling the aerosol, thus keeping the breathing pattern similar on both aerosol inhalation occasions.

The 11 normal subjects inhaled 4.5 and $0.3 \% \mathrm{NaCl}$ aerosols on separate occasions. The solutions contained approximately $200 \mathrm{MBq} \cdot \mathrm{ml}^{-1}$ of ${ }^{99 \mathrm{~m} t e c h n e t i u m-}$ diethyltriaminepentaacetic acid $\left({ }^{99 \mathrm{~m} T c-D T P A) . ~ T h e ~}\right.$ concentration of 99mTc-DTPA was adjusted to give the upper limit on radioactivity leaving the nebulizer of $100 \mathrm{MBq}$ per study (estimated maximal activity depositing in the respiratory tract for each study $=30 \mathrm{MBq}$ ). The maximum whole body effective dose equivalent for each of these studies was estimated to be $0.2 \mathrm{mGy}$ [28]. Both aerosols were delivered by the jet nebulizer driven with compressed oxygen at $8 l \cdot \mathrm{min}^{-1}$ over a period of about $3 \mathrm{~min}$. The subjects gargled, expectorated and then drank some water to remove the radioactivity from the mouth and the oesophagus.

Spirometry was performed prior to inhalation, and a single test (forced expiratory volume in one second $\left(\mathrm{FEV}_{1}\right)$ reported as \% predicted value) immediately after inhalation. Directly after the spirometry, each subject was placed in a supine position over a large field of view gamma camera (Diagnostomo, Philips, Hamburg, Germany) with a low energy all purpose collimator for one minute; posterior and anterior static scans followed by a 64 angle tomographic (SPECT) study of 12 min total duration. Two small ${ }^{99 \mathrm{~m}}$ technetium-pertechnetate markers were attached to the subject's chest to assist image alignment.

A transmission tomographic scan was performed to delineate the lung fields on a separate occasion. A flood source containing approximately $1.5 \mathrm{GBq}$ of ${ }^{153} \mathrm{Gd}$ in water was fixed to a frame mounted on the camera head [29]. With the subject in a supine position between the flood source and camera, a 64 angle tomographic study of the thorax was acquired in a $64 \times 64$ matrix. The attenuation images were then reconstructed to provide low definition anatomical data in the coronal plane.

\section{Penetration index (PI) of hyper- and isotonic aerosols} in asthmatic subjects

Unless described otherwise, the study design was identical to the PI determination in the group of normal subjects. The nine subjects inhaled isotonic and hypertonic $(4.5 \%)$ saline aerosols containing $99 \mathrm{mTc}$-DTPA on two separate occasions. The duration of inhalation was decided on a previous occasion, as the time to deliver the amount of hypertonic aerosol required to produce a maximum fall in $\mathrm{FEV}_{1}$ of $20 \%$ of the prechallenge value, with $5 \mathrm{~min}$ as the longest inhalation time.

The subjects were requested to cease all bronchodilator medication for at least $6 \mathrm{~h}$ prior to the aerosol inhalations. Spirometry was performed immediately before and after the aerosol inhalations. Bronchodilator aerosol was administered after the hypertonic aerosol if needed (only subjects Nos. 12 and 20 required it), otherwise, after the imaging was completed. 
Effect of clearance on the PI measurement during the SPECT acquisition time

A necessary condition in acquiring SPECT data is that the radionuclide distribution in the regions of interest does not change significantly during the $12 \mathrm{~min}$ acquisition period. One minute static anterior and posterior images were collected immediately before and after the tomographic scan in order to compare the change in the images during the acquisition.

\section{Data treatment for both studies}

A thick mid-lung coronal slice in the right lung was used to measure PI [23]:

$\% \mathrm{PI}=100 \times \mathrm{cpm}$ in peripheral region $/ \mathrm{cpm}$ in a central region $(\mathrm{cpm}=$ counts per minute $)$

where the central region was also modified to include the trachea (fig. 1).

The lung regions were defined on the basis of the transmission scans to delineate the lung boundaries. An example of the use of the transmission scan is shown in figure 2, which shows a central aerosol deposition pattern and the lung boundary derived from transmission tomography in subject No. 12.

In a previous study, large intersubject variation in PI was found even in normal subjects inhaling isotonic

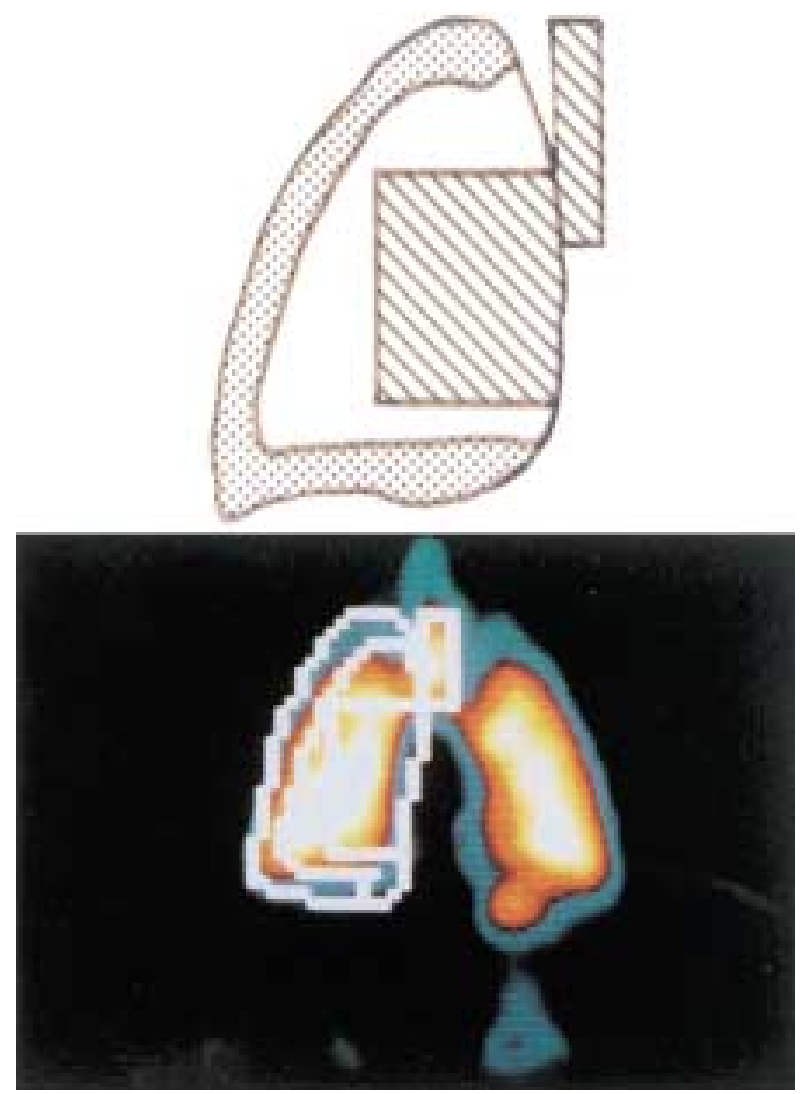

Fig. 1. - Regions of interest (ROI) for calculation of the penetration index. This anterior view shows ROI in the right lung. (Same orientation as in Figs. 3 and 4).
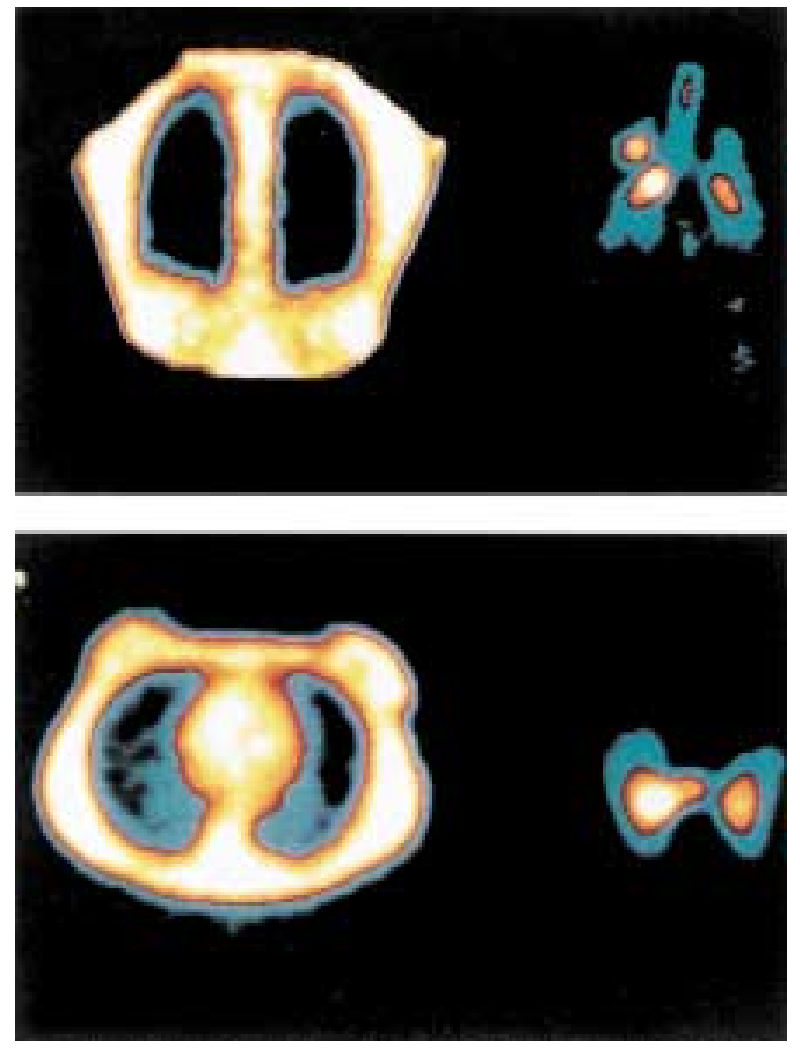

Fig. 2. - Transmission (on the left of the figure) and corresponding emission (on the right) images of subject No. 12. Coronal central slices are shown above transverse central slices in this figure. The aerosol has deposited centrally, as can be observed by comparison with the lung boundaries shown in the transmission images.

aerosols; however, the relative differences in PI (d(PI)), were found to be consistent comparing PI of aerosols with MMAD 2.6 and $5.5 \mu \mathrm{m}$ [23]. The relative difference $\mathrm{d}(\%)$ for a parameter $\mathrm{x}$ is defined as:

$$
\% \mathrm{~d}(\mathrm{x})=100 \times\left(\mathrm{x}_{1}-\mathrm{x}_{2}\right) / \mathrm{x}_{1}
$$

where $\mathrm{x}_{1}$ stands, e.g., for a parameter $\mathrm{x}$ measured on the hypotonic aerosol day in the normal group or isotonic aerosol day in the asthmatic group, and $\mathrm{x}_{2}$ stands for the value of the parameter on the hypertonic aerosol study day. The statistical significance of the d-values was assessed using one-tailed t-test and one-tailed Wilcoxon test [30].

\section{Results}

There was very little difference in any of the breathing parameters between inhalation occasions for all subjects (table 1). The coefficient of variation of the means of the breathing parameters in any one subject was less than $15 \%$. The difference in the mean parameters between the two inhalation occasions was also less than $15 \%$ for any one subject, with the exception of inspiratory pause which was mostly within $0.1 \mathrm{~s}$ on the two occasions (subject No. 15 had a difference of $0.2 \mathrm{~s}$ ). 
Table 1. - Mean breathing parameters for each subject (normal and asthmatic) with hypotonic/isotonic/hypertonic aerosol

\begin{tabular}{|c|c|c|c|c|c|c|c|c|c|c|}
\hline \multirow{3}{*}{$\begin{array}{l}\text { Subject } \\
\text { No. }\end{array}$} & \multicolumn{5}{|c|}{ Hypotonic or isotonic aerosol } & \multicolumn{5}{|c|}{ Hypertonic aerosol } \\
\hline & VT & PIF & PEF & Ttot & PI & $\mathrm{VT}_{\mathrm{T}}$ & PIF & PEF & Ttot & PI \\
\hline & & & & & $\mathrm{s}$ & & & & $\mathrm{s}$ & $\mathrm{s}$ \\
\hline \multicolumn{11}{|l|}{ Normal } \\
\hline 1 & 423 & 21.2 & 12.7 & 5.1 & 0.1 & 412 & 20.6 & 12.9 & 5.2 & 0.1 \\
\hline 2 & 660 & 24.4 & 25.1 & 3.8 & 0.22 & 579 & 21.6 & 22.9 & 3.8 & 0.21 \\
\hline 3 & 772 & 17.5 & 18.1 & 5.6 & 0.28 & 772 & 17.3 & 20.1 & 5.6 & 0.3 \\
\hline 4 & 550 & 14.7 & 21.8 & 3.6 & 0.24 & 478 & 12.9 & 20.6 & 3.7 & 0.22 \\
\hline 5 & 740 & 16.2 & 17.5 & 5.1 & 0.45 & 824 & 18.6 & 18.6 & 5.1 & 0.36 \\
\hline 6 & 633 & 16.8 & 17.0 & 6.0 & 0.16 & 634 & 17.6 & 15.0 & 6.0 & 0.1 \\
\hline 7 & 401 & 28.3 & 20.8 & 5.9 & 0.08 & 391 & 32.3 & 18.1 & 5.8 & 0.06 \\
\hline 8 & 748 & 28.4 & 29.0 & 4.4 & 0.22 & 669 & 26.0 & 30.1 & 4.2 & 0.19 \\
\hline 9 & 791 & 25.8 & 29.6 & 3.5 & 0.1 & 872 & 28.9 & 33.4 & 3.5 & 0.11 \\
\hline 10 & 449 & 12.8 & 12.6 & 4.7 & 0.51 & 416 & 13.3 & 12.3 & 4.7 & 0.58 \\
\hline 11 & 618 & 14.4 & 11.4 & 6.0 & 0.27 & 634 & 12.4 & 13.0 & 6.0 & 0.28 \\
\hline \multicolumn{11}{|c|}{ Asthmatic } \\
\hline 12 & 971 & 22.3 & 27.9 & 4.9 & 0.3 & 1003 & 25.4 & 32.1 & 4.6 & 0.22 \\
\hline 13 & 1005 & 35.9 & 29.2 & 5.4 & 0.19 & 1101 & 40.9 & 29.8 & 5.5 & 0.14 \\
\hline 14 & 710 & 35.8 & 24.0 & 4.4 & 0.15 & 752 & 38.4 & 26.5 & 4.4 & 0.11 \\
\hline 15 & 363 & 18.6 & 13.6 & 5.0 & 0.3 & 439 & 20.0 & 15.5 & 5.7 & 0.5 \\
\hline 16 & 1000 & 48.7 & 22.0 & 4.9 & 0.4 & 949 & 52.9 & 21.1 & 5.1 & 0.43 \\
\hline 17 & 422 & 11.0 & 16.8 & 3.8 & 0.22 & 428 & 9.6 & 16.2 & 3.8 & 0.13 \\
\hline 18 & 566 & 22.5 & 15.8 & 5.4 & 0.11 & 595 & 25.4 & 14.6 & 5.9 & 0.2 \\
\hline 19 & 441 & 16.4 & 22.7 & 3.1 & 0.08 & 484 & 19.9 & 22.0 & 3.0 & 0.06 \\
\hline 20 & 1894 & 71.5 & 35.8 & 6.8 & 0.06 & 1773 & 69.2 & 36.2 & 7.0 & 0.09 \\
\hline
\end{tabular}

VT: tidal volume; PIF: peak inspiratory flow rate; PEF: peak expiratory flow rate; Ttot: time of respiratory cycle; PI: inspiratory pause.

\section{PI of hypo- and hypertonic aerosols in normal subjects}

The pretest $\mathrm{FEV}_{1}$ values were greater than $96 \%$ of predicted and were similar to the post-test values for all subjects on all study days (intra- and interstudy day differences $<4.7 \%$ ). There was no statistically significant difference in PI between the hypo- and hypertonic

Table 2. - Normal subjects: tracheal counts as percentage of those in the right lung tomographic images $(\mathrm{TC}(\mathrm{T}))$ and geometric means of static images taken immediately after inhalation (TC(GM)); and penetration index $(\mathrm{PI})$ obtained by tomography with hypotonic/hypertonic aerosol. $\mathrm{d}(\mathrm{PI})$ calculated from Equation 1

\begin{tabular}{|c|c|c|c|c|c|c|c|}
\hline \multirow{2}{*}{$\begin{array}{l}\text { Sbjt } \\
\text { No. }\end{array}$} & \multicolumn{3}{|c|}{ Hypotonic } & \multicolumn{3}{|c|}{ Hypertonic } & \multirow[b]{2}{*}{$\mathrm{d}(\mathrm{PI})$} \\
\hline & $\mathrm{TC}(\mathrm{T})$ & $\mathrm{TC}(\mathrm{GM})$ & PI & $\mathrm{TC}(\mathrm{T})$ & $\mathrm{TC}(\mathrm{GM})$ & PI & \\
\hline 1 & 7.6 & 4.3 & 39.9 & 17.1 & 5.2 & 39.2 & 1.8 \\
\hline 2 & 4.1 & 5.7 & 43.5 & 16.1 & 13.8 & 34.8 & 20.0 \\
\hline 3 & 4.5 & 4.5 & 73.4 & 3.5 & 4.9 & 71.1 & 3.1 \\
\hline 4 & 3.0 & 4.9 & 46.3 & 4.5 & 4.6 & 46.3 & 0 \\
\hline 5 & 2.5 & 5.2 & 67.4 & 4.8 & 7.9 & 52.7 & 21.8 \\
\hline 6 & 6.5 & 7.2 & 42.9 & 7.8 & 5.4 & 47.0 & -9.6 \\
\hline 7 & 5.4 & 9.4 & 38.1 & 4.8 & 7.1 & 41.4 & -8.7 \\
\hline 8 & 8.3 & 9.7 & 36.7 & 16.1 & 15.5 & 35.3 & 3.8 \\
\hline 9 & 2.7 & 3.8 & 48.2 & 5.5 & 6.1 & 42.5 & 11.8 \\
\hline 10 & 7.4 & 7.0 & 53.0 & 16.6 & 14.6 & 46.3 & 12.6 \\
\hline 11 & 2.5 & 3.4 & 51.6 & 6.7 & 5.9 & 42.6 & 17.4 \\
\hline
\end{tabular}

Sbjt: subject. aerosols when the tracheal counts were excluded from the central region, as was done in our original study with isotonic aerosols [23]. It was noted, however, that there was significantly less activity in the trachea (as percentage of total right lung counts) with the hypotonic compared to the hypertonic studies: mean reduction $=$ median reduction $=94 \%$; $\mathrm{t}$-test $\mathrm{p}=0.003$; Wilcoxon test $\mathrm{p}=0.006$ (table 2 and fig. 3 ). This trend was also present with the static planar images taken immediately after inhalation (mean reduction $43 \%$; median reduction $52 \%$; t-test $\mathrm{p}=0.012$; Wilcoxon test $\mathrm{p}=0.023$ ) (table 2), indicating that the increased tracheal deposition

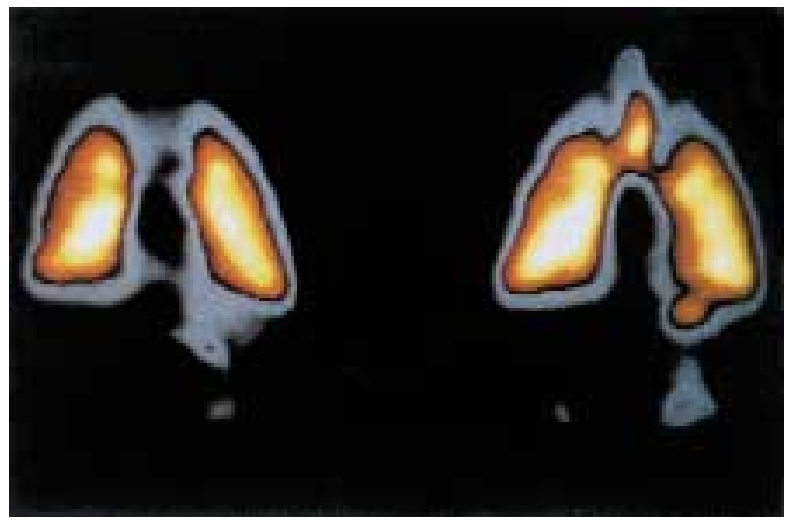

Fig. 3. - Mid-lung coronal images from the hypotonic (on the left) and hypertonic (on the right) aerosol studies in subject No. 1. Note the enhanced tracheal deposition in the hypertonic study. 
Table 3. - Asthmatic subjects: tracheal counts as percentage of those in the right lung (TC(T)) and penetration index (PI) obtained by tomography; baseline and postchallenge FEV

\begin{tabular}{|c|c|c|c|c|c|c|c|c|}
\hline \multirow{2}{*}{$\begin{array}{c}\text { Subject } \\
\text { No. }\end{array}$} & \multicolumn{4}{|c|}{ Isotonic } & \multicolumn{4}{|c|}{ Hypertonic } \\
\hline & $\mathrm{TC}(\mathrm{T})$ & PI & $\begin{array}{c}\text { Baseline } \\
\mathrm{FEV}_{1}\end{array}$ & $\begin{array}{c}\text { Post- } \\
\text { challenge } \\
\mathrm{FEV}_{1}\end{array}$ & $\mathrm{TC}(\mathrm{T})$ & PI & $\begin{array}{c}\text { Baseline } \\
\text { FEV }_{1}\end{array}$ & $\begin{array}{c}\text { Post- } \\
\text { challenge } \\
\mathrm{FEV}_{1}\end{array}$ \\
\hline 12 & 4.2 & 48.6 & 82 & 88 & 22.7 & 9.7 & 76 & 16 \\
\hline 13 & 1.8 & 37.6 & 98 & 101 & 37.8 & 13.9 & 101 & 84 \\
\hline 14 & 18.5 & 36.9 & 92 & 93 & 33.5 & 31.6 & 97 & 91 \\
\hline 15 & 5.1 & 39.5 & 118 & 119 & 14.7 & 22.5 & 118 & 117 \\
\hline 16 & 1.8 & 43.3 & 80 & 78 & 6.7 & 36.1 & 80 & 76 \\
\hline 17 & 11.3 & 28.5 & 70 & 76 & 26.3 & 20.8 & 74 & 80 \\
\hline 18 & 5.7 & 27.6 & 62 & 61 & 7.1 & 45.1 & 86 & 84 \\
\hline 19 & 7.3 & 21.8 & 73 & 71 & 7.6 & 32.9 & 79 & 74 \\
\hline 20 & 4.1 & 18.6 & 58 & 59 & 8.2 & 22.2 & 71 & 20 \\
\hline
\end{tabular}

$\mathrm{FEV}_{1}$ : forced expiratory volume in one second as $\%$ predicted.

with the hypertonic aerosol was unlikely to be due to mucociliary clearance during the acquisition time in the tomographic study.

Using the regions of interest shown in figure 1 (i.e. central region including the trachea), the mean and median relative differences in PI between the hypoand hypertonic studies were $\mathrm{d}=6.7 \%$ ( $\mathrm{t}$-test and Wilcoxon test $\mathrm{p}=0.03$ ) (table 2).

\section{PI of hyper-and isotonic aerosols in asthmatic subjects}

There was no significant bronchoconstriction as assessed by the post- versus pre- aerosol $\mathrm{FEV}_{1}$ when the subjects inhaled isotonic aerosols. The same was true for inhalation of the hypertonic aerosols, with the exception of subjects Nos. 12 and 20, who had postaerosol reductions of $\mathrm{FEV}_{1}$ by more than $50 \%$ (table 3). There was no systematic trend in the differences in PI between the hyper- and isotonic aerosols for the group of asthmatic subjects as a whole. However, a number of observations can be made on subgroups of subjects (table 4). Both the provoked fall in $\mathrm{FEV}_{1}$ (as a result of the hypertonic challenge) and hygroscopic growth of the hypertonic aerosol would be expected to result in a smaller PI (positive d). This was the case in subjects Nos. 12-17 (tables 3 and 4), who had differences in baseline $\mathrm{FEV}_{1}$ of less than $7 \%$. Figure 4 shows the effect of bronchoconstriction provoked by the hypertonic aerosol on regional deposition in subject No. 12. The perihilar deposition pattern is evident when airway narrowing reduces the aerosol penetration. Conversely, subjects Nos. 18-20 had a greater PI value for the hypertonic than the isotonic aerosol $(\mathrm{d}(\mathrm{PI})<0)$. These three subjects had a better baseline (prechallenge) $\mathrm{FEV}_{1}$ on the hypertonic day, which may account for this finding. On the other hand, positive $\mathrm{d}(\mathrm{PI})$ in subjects Nos. 1517 in conjunction with the small variations in baseline and postchallenge $\mathrm{FEV}_{1}$ for both study days would suggest that, as in normal subjects, hygroscopic growth may be the major cause of the lower penetration of the hypertonic aerosol in this subgroup.

Closer examination of table 4 shows that small changes in baseline lung function appear to be associated with the greatest differences in PI, and where the baseline $\mathrm{FEV}_{1}$ was greater on the hypertonic day (d $\left(\mathrm{FEV}_{1}\right)<0$ ), the PI was also generally greater on the hypertonic day $(\mathrm{d}(\mathrm{PI})<0)$, even though there could be

Table 4. - Changes (d) in $\mathrm{PI}$ and $\mathrm{FEV}_{1}$ for the asthmatic subjects with isotonic and hypertonic aerosol

\begin{tabular}{cccccc}
\hline $\begin{array}{c}\text { Subject } \\
\text { No. }\end{array}$ & $\mathrm{d}(\mathrm{PI})$ & $\begin{array}{c}\text { Isotonic aerosol: } \\
\text { \% change in FEV } \\
\text { during test }\end{array}$ & $\begin{array}{c}\text { Hypertonic aerosol } \\
\text { \% change in FEV } \\
\text { during test }\end{array}$ & $\begin{array}{c}\text { Baseline } \\
\mathrm{d}\left(\mathrm{FEV}_{1}\right)\end{array}$ & $\begin{array}{c}\text { Post- } \\
\text { challenge } \\
\mathrm{d}\left(\mathrm{FEV}_{1}\right)\end{array}$ \\
\hline 12 & 80.0 & -7.4 & 79.1 & 6.9 & 81.9 \\
13 & 63.0 & -2.4 & 16.2 & -2.4 & 16.2 \\
14 & 14.7 & -0.4 & 6.2 & -4.7 & 2.4 \\
15 & 43.0 & -0.8 & 0.8 & 0.0 & 2.7 \\
16 & 16.6 & 3.0 & 4.8 & 0.4 & -6.3 \\
17 & 27.1 & -7.5 & -8.5 & -37.6 & -36.7 \\
18 & -63.4 & 1.6 & 2.2 & -8.3 & -4.7 \\
19 & -50.9 & 3.6 & 6.8 & -21.7 & 65.9 \\
20 & -19.4 & -2.1 & 71.4 & & \\
\hline
\end{tabular}

d-values calculated as: $\mathrm{d}=\left(\mathrm{x}_{1}-\mathrm{x}_{2}\right) \times 100 / \mathrm{x}_{1}$ where $\mathrm{x}_{1}$ is a parameter (baseline $\mathrm{FEV}_{1}$, post aerosol $\mathrm{FEV}_{1}$ or PI) on the isotonic day and $\mathrm{x}_{2}$ is the same parameter on the hypertonic day. PI: penetration index; FEV ${ }_{1}$ : forced expiratory volume in one second, positive change indicates fall in $\mathrm{FEV}_{1}$. 


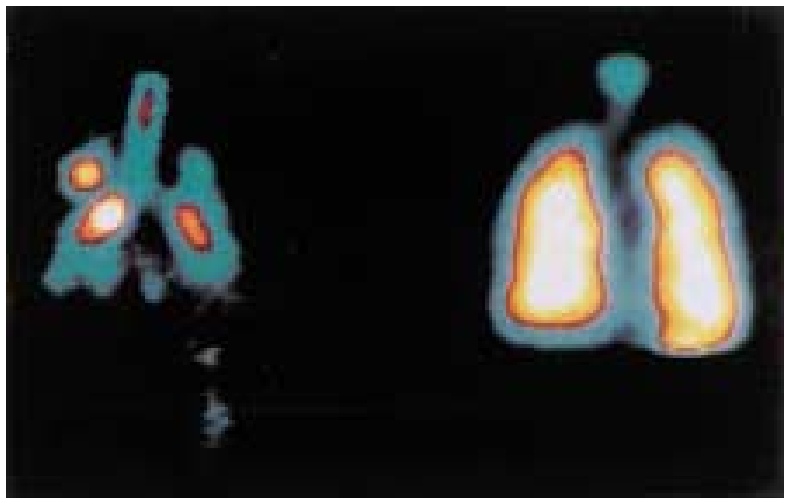

Fig. 4. - Mid-lung coronal slices following the administration of the hypertonic (on the left) and isotonic (on the right) aerosols for subject No. 12. Note the effect of bronchoconstriction provoked by the hypertonic aerosol on the deposition pattern.

a marked bronchoconstriction on that day (subject No. $20)$. Indeed, there was a significant correlation $\left(r^{2}=0.66\right)$ between the relative change in the penetration index, $\mathrm{d}(\mathrm{PI})$, and the relative change in the baseline $\mathrm{FEV}_{1}$, $\left(\mathrm{d}\left(\mathrm{FEV}_{1}\right)\right)$; the correlation between $\mathrm{d}(\mathrm{PI})$ and postchallenge $d\left(F_{E V}\right)$ was poor $\left(r^{2}=0.25\right)$ (fig. 5).

Again, of particular note was the fact that the $\%$ counts in the trachea were greater on the hypertonic day for every asthmatic subject (table 3 ). The relative change in the $\%$ tracheal count between the two study days in the asthmatics was more prominent than in the group of normal subjects (d-value: mean $=360 \%$; median $=133 \%$; t-test $\mathrm{p}=0.06$; Wilcoxon test $\mathrm{p}=0.005)$.

Analysis of PI obtained from the static posterior images acquired immediately before and after the SPECT study was available for nine of the normal and five of the asthmatic subjects. Similarly, we analysed PI evaluated from the first and the last (sixty fourth) frame of the SPECT study in these subjects; although these two frames do not exactly match the same anatomical regions, they nevertheless provided us with an opportu-

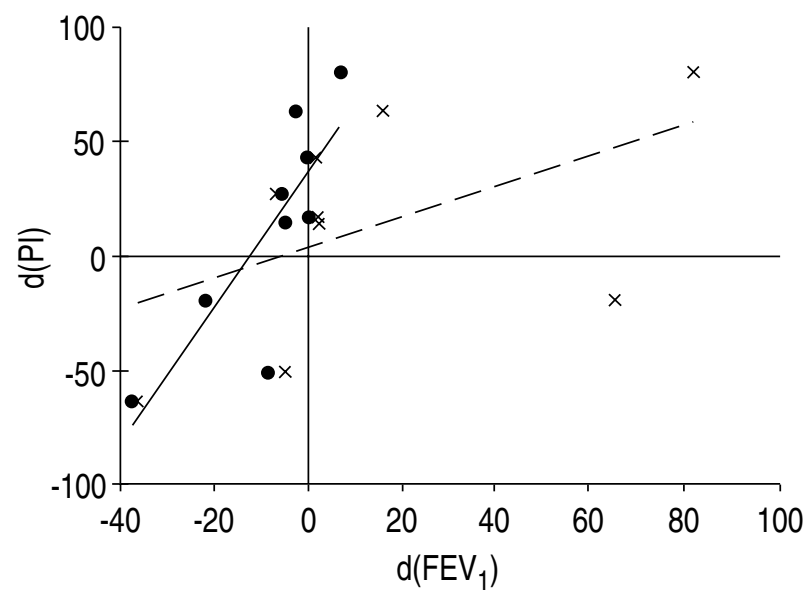

Fig. 5. - Correlation between the relative difference in the penetration index $(\mathrm{d}(\mathrm{PI}))$ of the hypertonic and isotonic aerosols, and the relative difference $\left(\mathrm{d}\left(\mathrm{FEV}_{1}\right)\right)$ in the prechallenge (baseline) $\mathrm{FEV}_{1}(\bullet$ : experimental points, solid line fitted by linear regression), or postchallenge $\mathrm{FEV}_{1}$ ( $\mathbf{x}$ : experimental points, broken line fitted by regression analysis) in asthmatic subjects. $\mathrm{FEV}_{1}$ : forced expiratory volume in one second. nity to check the clearance effects in an approximate way. The relative difference $\mathrm{d}$ (Equation (1)), with $\mathrm{x}_{1}=$ post-SPECT PI (i.e. PI from the last frame of the SPECT study) and $\mathrm{x}_{2}=$ pre-SPECT PI (or PI from the first frame of the SPECT study), thus calculated was found to be significantly different from zero $(\mathrm{p}<0.05$ by either the paired t-test, or by the Wilcoxon test) only when PI was obtained from the posterior images in the hypotonic aerosol experiments in the normal subjects (mean value of $\mathrm{d}=-14.2 \%$ ).

\section{Discussion}

This is the first study to investigate the regional deposition of aqueous aerosols of different tonicities both in normal and asthmatic subjects. Our studies were facilitated by the use of the tomographic method for evaluation of differences in PI; this was almost twice as sensitive as the anterior-posterior views (results not shown), in agreement with our previous findings [23]. In the asthmatic subjects, it was found that the state of the airways just prior to the inhalation of the aerosol, as well as the bronchoconstriction caused by the hypertonic aerosol, were the important determinants of the regional pattern of deposition. These findings have implications for interpretation of results of tests of bronchial hyperresponsiveness where aerosols of different tonicities are used [31, 32].

Using similar techniques to those used in the study described here, isotonic aerosols with either "small" or "large" droplets (MMAD 2.6 vs $5.5 \mu \mathrm{m}$ ) were shown to deposit with markedly different PI values in normal individuals [23]. We wished to compare those results with the current observations, in which significant differences in the deposition of aerosols containing solutions of different tonicity were found in the tracheal region. The regions of interest in the previous study [23] were, therefore, modified to include the trachea as part of the central region (fig. 1). The PI values for the small and large isotonic droplet aerosols [23] were recalculated using the modified regions of interest with

Table 5. - Penetration index (PI) values for large (5.5 $\mu \mathrm{m})$ and small $(2.6 \mu \mathrm{m})$ isotonic droplet inhalation studies in seven normal subjects

\begin{tabular}{cccc}
\hline $\begin{array}{c}\text { Sbt } \\
\text { No. }\end{array}$ & Small droplets & Large droplets & d-values \\
\hline 1 & & & \\
2 & 62.2 & 24.4 & 60.8 \\
3 & 44.0 & 28.4 & 35.5 \\
4 & 36.1 & 15.1 & 58.2 \\
5 & 71.3 & 35.7 & 49.9 \\
6 & 56.8 & 23.8 & 58.1 \\
7 & 71.4 & 33.1 & 53.6 \\
\hline
\end{tabular}

$\mathrm{d}$-value in this case is defined as (small - large/small) $\times 100$; i.e. percentage fall in PI from small to large droplet study. For abbreviations see legend to table 4. Data from [23] but the results presented here include tracheal counts in the central region. 


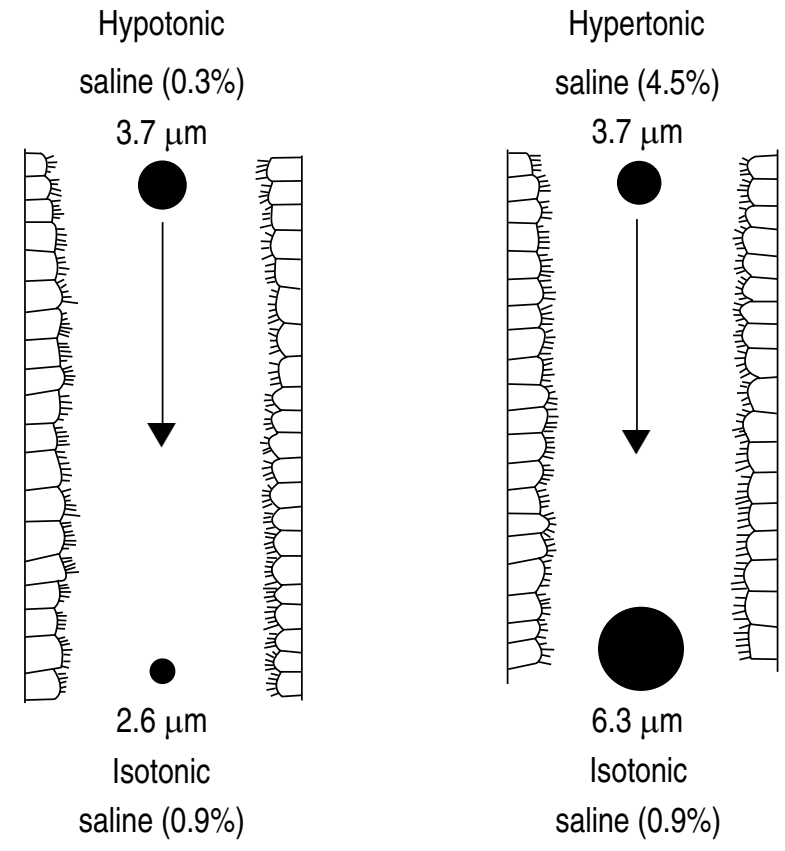

Fig. 6. - Diagramatic representation of hygroscopic growth and shrinkage to equilibrium size (i.e. to isotonic composition) of hyperand hypotonic droplets of the same initial size $(3.7 \mu \mathrm{m})$ in the respiratory tract.

central coronal slices. The mean relative difference, $\mathrm{d}$ (Equation (1) with $\mathrm{x}_{1}=\mathrm{PI}$ from the small droplet study, $\mathrm{x}_{2}=\mathrm{PI}$ from the large droplet study) in PI was, thus, found to be $55 \%$ (t-test $\mathrm{p}<0.001$; median $56 \%$; Wilcoxon test $\mathrm{p}=0.011)$ (table 5), compared to $\mathrm{d}=6.7 \%(\mathrm{p}=0.03)$ in the current study (raw data, table 2 ). The calculated median equilibrium sizes, at the relative humidity corresponding to isotonic saline at $37^{\circ} \mathrm{C}$, of the hypo- and hypertonic aerosol droplets used in this study are 2.4 and $6.3 \mu \mathrm{m}$, respectively, (fig. 6) [9]. If equilibration had taken place immediately upon the aerosol entering into the respiratory tract, then the differences in the PI would have been expected to be at least as great as those found in the previous investigations using 2.6 and $5.5 \mu \mathrm{m}$ isotonic aerosol droplets [23].

There are a number of reasons which could explain why the difference in PI is less than that assumed on the basis of such instantaneous equilibration with the airway fluid: 1) The fluid lining the upper airways is thought to be hypertonic (by $\sim 10 \%$ in dog trachea [33]), so this will somewhat reduce the driving force for hygroscopic droplet growth, but the evaporation of the hypotonic droplets would be increased. 2) The growth and evaporation rates are such that significant size changes would be taking place during the transit of the aerosol through the airways [3]. The changes cannot be assumed to occur instantaneously. This would tend to reduce the difference between the PI obtained with different tonicities. 3) The water for the growth of hypertonic droplets is provided by evaporation from the airway surface, which can become hypertonic. If this happened, the equilibrium diameter would then be smaller as the airway fluid osmolarity approaches that of the droplets, and the drive for hygroscopic growth would be reduced. The opposite would occur for the hypotonic aerosol. Deposition of nonisotonic droplet prior to equilibration will have analogous effects. 4) The aerosol cloud carries with it vapour. This will act as a buffer counteracting the unequal vapour pressure of the airway fluid. This buffering effect will be greater the greater the density (number of droplets per unit volume of the carrier air) of the aerosols $[9,34]$. 5) Clearance during data acquisition could contribute to the reduction in the apparent difference in PI between aerosols of different tonicities. Over the period of time in our experiments, about $10-20 \%$ of the radioactivity would be expected to be cleared from the central and peripheral regions, both in normal and in asthmatic subjects [35, 36]. Mucociliary clearance (MCC) was shown to be faster after nonisotonic aerosols $[37,38]$. Both the central and the peripheral regions will have some loss of radioactivity during the image acquisition; however, the central region also gains some radioactivity by $\mathrm{MCC}$ into it from the more distal parts of the respiratory tract.

Absorption of the label is likely to be faster from the peripheral compared to the central regions [35]. Overall, there should be a decrease in the PI during the acquisition, and this reduction should be greater for the aerosol with the higher initial PI (i.e. the hypotonic aerosol in the normals). This trend was, indeed, observed in the normal subjects, but it did not reach statistical significance except in the hypotonic experiment, when the PI was evaluated from the static posterior image. Because the decrease in PI during the SPECT image acquisition was observed both with hypo- and hypertonic aerosols, we do not think that our qualitative conclusions regarding the difference in PI between the hypo- and hypertonic aerosols are affected by the clearance. We found a greater decrease in PI during image acquisition for the hypotonic aerosols, suggesting that the initial difference in the regional deposition of hyper- and hypotonic aerosols in normal subjects is probably greater than that observed by us.

No conclusions could be drawn from the pre- and post-SPECT studies with the asthmatic subjects about the effect of MCC on the observed values of PI.

The modification of the composition of the airway fluid by the deposited aerosol and, in turn, the potential consequences of this action on the hygroscopic growth, deposition and bronchoconstriction, could be minimized by carrying out the experiments with aerosols containing a small number of droplets ("hypodense" aerosols) [39].

Persons et al. [15], using a theoretical model, calculated the fractional deposition of $4 \mu \mathrm{m}$ droplets of 4.5 and $0.45 \% \mathrm{NaCl} \quad\left(\sigma_{\mathrm{g}}=1.8 ;\right.$ breathing frequency $=15$ breaths $\cdot \mathrm{min}^{-1}$; and tidal volume $=1,000 \mathrm{ml}$, assuming a relative humidity of $85 \%$ for mouth and pharynx and $99.5 \%$ for lung). The predicted deposition fractions show similar alveolar deposition for both aerosols (31 vs $28 \%$ ) but a greater proportion of tracheobronchial deposition for the hypertonic aerosol than the hypotonic (20 vs 12\%). These predictions are confirmed in a semiquantitative way by our results. However, the assignments of the regions in the model and experiment are 
not identical. The model does not take into account the possible effect of the aerosol on the airway fluid (i.e. change of tonicity) and it only treats the limiting case of a single droplet passing through the respiratory tract. Realistic models for deposition of nonisotonic aerosols should take into account the interaction between the aerosol droplets, the surrounding atmosphere and the airway fluid $[34,40]$.

Many therapeutic, diagnostic and environmental aerosols are hygroscopic in nature, for example dry powders of drugs [4, 11, 41], and some nebulizer solutions [5]. Even droplets generated from isotonic nebulizer solutions may become hypertonic before reaching the airways [9].

Airway narrowing alters regional deposition in favour of the large airways [21, 42-44], in studies where bronchoconstriction was deliberately induced prior to administering the imaging aerosol. One of our aims was to assess the effects of baseline lung function and bronchoconstriction during the challenge test on regional deposition. Six of the nine asthmatic subjects (subjects Nos. 12-17) had $d>0$ for PI. In three of these, there was a direct relationship between the differences in \%

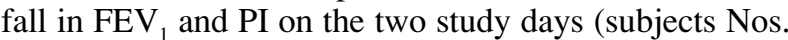
12-14). Only in 3 of the 6 subjects with d values for PI $>0$ (subjects Nos. 15-17) could we suggest that hygroscopic growth may be the major cause of the lower penetration of the hypertonic aerosol.

In conclusion, this study shows that for proper physiological understanding of bronchial hyperresponsiveness, it is necessary to bear in mind not only the effects of nonisotonic aerosols on the airways but also the dynamic influence of the airway environment on the properties and deposition of the aerosol.

\section{References}

1. Muller WJ, Hess GD, Scherer PW. A model of cigarette smoke particle deposition. Am Ind Hyg Assoc J 1990; 51: 245-256.

2. Cocks AT, Fernando R. The growth of sulphate aerosols in the human airways. J Aerosol Sci 1982; 13: 9-19.

3. Morrow PE. Factors determining hygroscopic aerosol deposition in airways. Physiol Rev 1986; 66: 330-376.

4. Gonda I, Kayes JB, Groom CV, Fildes FJT. Characterisation of hygroscopic inhalation aerosols. In: StanleyWood NG, Allen T, eds. Particle Size Analysis, 1981. Chichester, Wiley Heyden Ltd, 1982; pp. 31-43.

5. Fois RA, Gonda I, Chan H-K. Tonicity of some commonly used drug preparations for nebulisation. Aust $J$ Hosp Pharm 1986; 16: 19-21.

6. Schoeffel RE, Anderson SD, Altounyan REC. Bronchial hyperreactivity in response to inhalation of ultrasonically nebulised solutions of distilled water and saline. Br Med J 1981; 283: 1285-1287.

7. Anderson SD, Schoeffel RD, Finney M. Evaluation of ultrasonically nebulized solutions for provocation testing in patients with asthma. Thorax 1983; 38: 284-291.

8. Stahlhofen W, Gebhart J, Heyder J, Scheuch G. Deposition pattern of droplets from medical nebulizers in the human respiratory tract. Bull Eur Physiopathol Respir 1983; 19: 459-463.
9. Phipps PR, Gonda I. Some consequences of instability of aqueous aerosols produced by jet and ultrasonic nebulizers. Proceedings of the 3rd International Aerosol Conference, September 24-27, 1990, Kyoto, Japan. In: Masuda S, Takahashi K, eds. Aerosols: Science, Industry, Health and Environment. Oxford, Pergamon Press, 1990; Vol. 1: pp. 227-230.

10. Phipps PR, Gonda I, Bailey DL, Anderson SD, Bautovich G. Penetration index (PI) of hypertonic $(\mathrm{H})$ and isotonic (I) aerosols in asthmatics. 8th Congress of the International Society for Aerosols in Medicine, Davos, Switzerland, April 1991. J Aerosol Med 1991; 4 (Suppl. 1): 24.

11. Hickey AJ, Martonen TB. Behavior of hygroscopic pharmaceutical aerosols and the influence of hydrophobic additives. Pharm Res 1993; 10: 1-7.

12. Ferron GA. The size of soluble aerosol particles as a function of the humidity of the air. Application to the human respiratory tract. J Aerosol Sci 1977; 8: 251267.

13. Ferron GA, Haider B, Kreyling WG. Aerosol particle growth in the human airways using a calculated humidity profile. J Aerosol Sci 1988; 19: 611-631.

14. Martonen TB, Bell KA, Phalen RF, Wilson AF, Ho A. Growth rate measurements and deposition modelling of hygroscopic aerosols in human tracheobronchial models. Ann Occup Hyg Assoc J 1982; 26: 93-107.

15. Persons DD, Hess GD, Muller WJ, Scherer PW. Airway deposition of hygroscopic heterodispersed aerosols: results of a computer calculation. J Appl Physiol 1987; 63: 1195-1204.

16. Persons DD, Hess GD, Scherer PW. Maximization of pulmonary hygroscopic aerosol deposition. J Appl Physiol 1987; 63: 1205-1209.

17. Dautrebande L, Walkenhorst T. Über die Retention von Kochsalzteilchen in den Atemwegen. In: Davies CN, ed. Inhaled Particles and Vapours. Oxford, Pergamon, 1960; pp. 110-120.

18. Hicks JF, Pritchard JN, Black A, Megaw WJ. Experimental evaluation of aerosol growth in the human respiratory tract. In: Aerosols: Formation and Reactivity. Proceedings of the 2nd International Aerosol Conference, Oxford, Pergamon, 1986; pp. 244-247.

19. Anselm A, Gebhart J, Heyder J, Ferron G. Human inhalation studies of hygroscopic particles in the respiratory tract. In: Aerosols, Formation and Reactivity. New York, Pergamon Press, 1986; pp. 252-255.

20. Anselm A, Heibel J, Gebhart J, Ferron G. "In vivo" studies of growth factors of sodium chloride particles in the human respiratory tract. J Aerosol Sci 1990; 21 (Suppl. 1): S427-S430.

21. Laube BL, Swift DL, Wagner HN, Norman PS, Adams GK. The effect of bronchial obstruction on central airway deposition of a saline aerosol in patients with asthma. Am Rev Respir Dis 1986; 133: 740-743.

22. Ruffin RE, Dolovich MB, Wolff RK, Newhouse MT. The effects of preferential deposition of histamine in the human airway. Am Rev Respir Dis 1978; 117: 485492.

23. Phipps PR, Gonda I, Bailey DL, Borham P, Bautovich $\mathrm{G}$, Anderson SD. Comparisons of planar and tomographic gamma scintigraphy to measure the penetration index of inhaled aerosols. Am Rev Respir Dis 1989; 139: 1516-1523.

24. Phipps PR, Gonda I. Droplets produced by medical nebulizers: some factors affecting their size and solute concentration. Chest 1990; 97: 1327-1332. 
25. Phipps P, Borham P, Gonda I, Bailey D, Bautovich G, Anderson S. A rapid method for the evaluation of radioaerosol delivery systems. Eur J Nucl Med 1987; 13: $183-186$.

26. Phipps PR, Gonda I, Anderson SD. Apparatus for the control of breathing pattern during aerosol inhalation. $J$ Aerosol Med 1992; 5; 155-170.

27. Phipps PR. Characterisation and Pulmonary Deposition of Therapeutic and Diagnostic Aqueous Aerosols. PhD Thesis, University of Sydney, Sydney, Australia, 1990.

28. Barber RW. Radiation doses from 99 mtechnetium-DTPA administered as an aerosol. J Nucl Med 1985; 26: 1190-1194.

29. Bailey DL, Hutton BF, Walker PJ. Improved SPECT using simultaneous emission and transmission tomography. J Nucl Med 1987; 28: 844-851.

30. Minitab Reference Manual. Release 7, Minitab Inc., State College, PA, 1989; Chp. 6 and 10.

31. Smith CM, Anderson SD. Inhalation provocation tests using nonisotonic aerosols. J Allergy Clin Immunol 1989; 84: 781-790.

32. Finney MJ, Anderson SD, Black JL. Terfenadine modifies airway narrowing induced by the inhalation of nonisotonic aerosols in subjects with asthma. Am Rev Respir Dis 1990; 141: 1151-1157.

33. Boucher RC, Stutts MJ, Bromberg PC, Gatzy JT. Regional differences in airway surface liquid composition. J Appl Physiol: Respirat Environ Exercise Physiol 1981; 50: 613-620.

34. Eisner AD, Graham RC, Martonon TB. Coupled mass and energy transport phenomena in aerosol/vapor-laden gases. I. Theory of the hygroscopic aerosol effects on temperature and relative humidity patterns of inspired air. J Aerosol Sci 1990; 21: 833-848.

35. Ilowite JS, Bennett WD, Sheetz MS, Groth ML, Nierman DM. Permeability of the bronchial mucosa to
99mTc-DTPA in asthma. Am Rev Respir Dis 1989; 139: 1139-1143.

36. Bennett WD, Ilowite JS. Dual pathway clearance of 99mTc-DTPA from the bronchial mucosa. Am Rev Respir Dis 1989; 139: 1132-1138.

37. Pavia D, Sutton PP, Lopez-Vidriero MT, Agnew JE, Clarke SW. Drug effects on function. Eur J Respir Dis 1983; 64 (Suppl. 127): 304-317.

38. Pavia D. Lung mucociliary clearance. In: Clarke SW, Pavia D, eds. Aerosols and the Lung: Clinical and Experimental Aspects. London, Butterworths, 1984; pp. 127-155.

39. Chan H-K, Phipps PR, Gonda I, Cook P, Fulton R, Young I, Bautovitch G. Regional deposition of nebulized hypodense nonisotonic solutions in the human respiratory tract. Eur Respir J 1994; 7: 1483-1489.

40. Gonda I. Therapeutic and diagnostic aerosols for delivery of agents to the respiratory tract. CRC Crit Rev Therap Drug Carrier Syst 1990; 6: 273-313.

41. Smith G, Hiller C, Mazumder M, Bone R. Aerodynamic size distribution of cromolyn sodium at ambient and airway humidity. Am Rev Respir Dis 1980; 121: 513-517.

42. Richards R, Haas A, Simpson S, Britten A, Renwick A, Holgate S. The effect of methacholine induced bronchoconstriction on the pulmonary distribution and plasma pharmacokinetics of inhaled sodium cromoglycate in subjects with normal and hyperreactive airways. Thorax 1988; 43: 611-616.

43. Pavia D, Thompson ML, Clarke SW, Shannon HS. Effect of lung function and mode of inhalation on penetration of aerosol into the human lungs. Thorax 1977; 32: 194-197.

44. Dolovich MB, Sanchis J, Rossman C, Newhouse MT. Aerosol penetrance: a sensitive index of peripheral airways obstruction. J Appl Physiol 1976; 40: 468-471. 